\title{
Os movimentos populares e o fetiche da participação no governo Lula
}

Cibele Maria Lima Rodrigues

Resumo: O Conselho Nacional das Cidades (Brasil) é composto por representantes dos governos, de ONGs, organizações empresariais, entidades acadêmicas e movimentos populares nacionais (envolvidos na luta por moradia). No processo de representação, os agentes que atuam no Conselho têm modificado suas identidades e discursos (Laclau e Mouffe). Os movimentos se articulam em uma rede com ONGs e entidades acadêmicas, mantendo a hegemonia dentro do Conselho e conseguindo mudanças em termos de recursos, legislação e reconhecimento da legitimidade das demandas populares. Porém, as decisões governamentais podem ignorar as decisões do Conselho, porque há relações de poder e hegemonia fazendo com que essa participação se torne um fetiche (Gramsci).

Palavras-chave: Conselho; Política urbana; Movimentos populares.

Abstract: The National Council of Cities (Brazil) is composed by representants of govnerment, NGOs, business organizations, academic entities and national popular movements (that are envolved with fight for housing). In the representation process, the agents that are in the Council have modified their identities and discourses (Laclau and Mouffe). The movements are linked in a network with NGO's e academic entities, maintained the hegemony, inside the Council, and give obtained changes in terms of resources, laws and recognition of the popular demands. But, the government decisions can ignore the decisions of the Council, because there are relations of power and hegemony that become this participation in a fetish (Gramsci).

Keywords: Council; Urban policy; Popular movements.

\section{INTRODUÇÃO}

A proposta deste artigo é discutir o jogo de identidades existente na intervenção dos movimentos sociais que lutaram por moradia ${ }^{1}$ no Conselho das Cidades durante a gestão do presidente Lula. A análise valeu-se do referencial definido por Laclau, Mouffe e Rancière, tendo como pano de fundo a cultura política. Nessa perspectiva, o referido Conselho é visto como uma cena política em que há um jogo de identidades atravessadas por hegemonia, antagonismo e ambiguidades. ${ }^{2}$ Ele é, ainda, um espaço de representação

\footnotetext{
*Fundação Joaquim Nabuco. Contato: cibele.rodrigues@fundaj.gov.br.

${ }^{1}$ A pesquisa foi realizada nos anos de 2007 e 2008, com análise das atas dos conselhos e dos demais documentos disponíveis na página do ministério, bem como da observação participante na Conferência Nacional das Cidades, em 2007, na qual foram realizadas entrevistas com as principais lideranças e com o então ministro das Cidades (Márcio Fortes). A observação na Conferência propiciou o acesso aos discursos de autoridades, como o presidente Lula, lideranças políticas, acadêmicos e empresários, que também entraram no rol para a composição da análise.

2 LACLAU, Ernesto; MOUFFE, Chantal. Beyond the positivity of the social: antagonisms and hegemony. In: . Hegemony and socialist strategy. London: Verbo, 2001. p. 93-148.
} 
política; nesse sentido, concordamos com $\operatorname{Laclau}^{3}$ que a representação não é uma relação translúcida entre representantes e representados, pois as demandas precisam ser inseridas num conjunto complexo de relações de poder que força os representados a tomar decisões, a partir do que lhes parece possível e necessário. É considerado o caráter simbólico e transitório da necessidade, tal como definido por Lacan, ${ }^{4}$ adotado por Laclau. ${ }^{5}$ Há que se considerar que esse processo se torna ainda mais complexo num contexto em que a política é o campo no qual domina a lógica do pragmatismo e entra em contraste com o discurso, que podemos denominar de "revolucionário", dos sujeitos considerados do campo dos movimentos populares, tal como analisou Doimo. ${ }^{6}$

Foram analisadas as formas de intervenção dos movimentos sociais que lutaram por moradia no Conselho no período de 2004 a 2007, a partir do pressuposto que, em uma configuração hegemônica específica, há fixação de sentidos em torno de significantes que funcionam como "pontos nodais", nos quais seu caráter particular se apresenta como se fosse universal. Segundo Mutzenberg, ${ }^{7}$ as manifestações coletivas podem expressar diferentes posicionamentos em relação a uma configuração dominante: (1) podem ser de aderência, numa forma de naturalização de padrões de comportamento; (2) podem ser manifestações de conflito, no interior de uma lógica hegemônica; (3) manifestações de posições antagônicas (quando os sentidos fixados são negados e novos sentidos são propostos). São três formas analíticas que podem evoluir em diferentes direções. Podemos sublinhar que o antagonismo vai surgir como quebra da linguagem natural, do senso comum, tal como define Gramsci. ${ }^{8} \mathrm{Na}$ ação política, "diferentes marcos de referência e repertórios são mobilizados e que remetem a processos políticos sedimentados no campo das relações sociais e numa cultura política". ${ }^{9}$

No Brasil, temos que considerar ainda o que assinala Castro ${ }^{10}$ sobre a existência de, ao menos, dois paradoxos ao tratarmos de cultura política e comportamento político. 0 primeiro se refere à institucionalização da democracia enquanto forma (procedimentos) e à continuidade de valores e atitudes não democráticas (fenômeno que poderia ser interpretado como uma "fraca adesão", nos termos de Gramsci). O segundo se refere à aceitação da democracia minimalista, dissociando sistema político e problemas sociais (as

\footnotetext{
${ }^{3}$ LACLAU, Ernesto. Poder e representação. Estudos Sociedade e Agricultura, n. 7, p. 7-28, dez. 1996.

${ }^{4}$ LACAN, Jacques. O estádio do espelho como formador de função do Eu. In: ZIZEK, Slavoj (ed.). Um mapa da ideologia. Rio de Janeiro: Contraponto, 1996, p. 97-104.

${ }^{5}$ LACLAU, Ernesto. Nuevas reflexiones sobre la revolución de nuestro tiempo. In: LACLAU, Ernesto. Nuevas reflexiones sobre la revolución de nuestro tiempo. Buenos Aires: Nueva Visión, 1990, p. 19-99.

6 DOIMO, Ana Maria. Movimento popular no Brasil pós-70: formação de um campo ético-político. Tese (Doutorado em Ciência Política), Departamento de Ciência Política, Universidade de São Paulo, São Paulo, 1993.

${ }^{7}$ MUTZENBERG, Remo. Ações coletivas, movimentos sociais: aderências, conflitos e antagonismo social. Tese (Doutorado Sociologia), Departamento de Ciências Sociais, Universidade Federal de Pernambuco, Recife, 2002.

${ }^{8}$ GRAMSCl, Antonio. Cadernos do cárcere, v. 1. Rio de Janeiro: Civilização Brasileira, 2001.

${ }^{9}$ MUTZENBERG, op. cit., p. 203.

${ }^{10}$ CASTRO, Henrique Carlos de Oliveira de. Cultura política, democracia e hegemonia: uma tentativa da explicação do comportamento político não democrático. In: BAQUERO, Marcello; CASTRO, Henrique Carlos de Oliveira; GONZÁLEZ, Rodrigo Stumpf (org.). A construção da democracia na América Latina: estabilidade democrática, processos eleitorais, cidadania e cultura política. Porto Alegre: UFRGS: La Salle, 1998.
} 
desigualdades econômicas). Então, se estabelece uma aceitação difusa dos "procedimentos democráticos". Para explicar tais paradoxos, a teoria de hegemonia, em Gramsci, inclui a ideia de que existe no senso comum uma visão fragmentada da realidade, pois num determinado bloco histórico, a liderança hegemônica constitui um consenso, naturalizando a dominação. A dominação mais importante para os "dirigentes" é a econômica, por isso, pode haver negociações no campo da política, ampliando a cidadania sem mudar a estrutura econômica. Na leitura feita por Laclau e Mouffe, ${ }^{11}$ o conceito de hegemonia é repensado numa perspectiva pós-estruturalista, reconhecendo as fraturas existentes nos blocos históricos que propiciam processos de mudanças, sem, necessariamente, a determinação econômica. Tais processos foram assinalados por autores como Stuart Hall. ${ }^{12}$

Laclau $^{13}$ apresenta o caráter mítico de determinados discursos que podem ser naturalizados, mas há possibilidades de contestação. Nesse sentido, concordamos com Lamounier $^{14}$ que as ideias de democracia e representação no Brasil esbarram numa visão "compartilhada pela direita autoritária e por setores de esquerda": uma perspectiva instrumental dos procedimentos formais de representação. Para a direita, essa visão faz com que conflitos, lutas sociais e reivindicações não sejam aceitos como legítimos ao longo da história, ${ }^{15}$ como mostram os processos de criminalização das lutas sociais em toda a América Latina. ${ }^{16}$ Essa visão é hegemônica e está sedimentada (mesmo que precariamente).

Nessa acepção, as demandas "populares" não estão no rol das coisas justas (e racionais), como diria Rancière. ${ }^{17}$ Por isso, mesmo que possa haver espaços de "participação" (como conselhos), não há garantias de sua importância no jogo político. Não há como prever os desdobramentos de tais processos, sobretudo se considerarmos a cultura política hegemonicamente autoritária. ${ }^{18}$ Não obstante, o que aconteceu foi que espaços de participação e controle social se proliferaram a partir da Constituição de 1988, no período de redemocratização após a ditadura militar, como em diversos países na América Latina. A democracia possível foi se constituindo em meio à cultura política, com todas as contradições já citadas.

Os movimentos sociais, sobretudo os populares, têm atuado de forma decisiva nos processos políticos, ao colocar as demandas no jogo, desafiando os códigos culturais

\footnotetext{
${ }^{11}$ LACLAU; MOUFFE, op. cit.

${ }^{12}$ HALL, Stuart. Da Diáspora: identidades e mediações culturais. Belo Horizonte: UFMG, 2003, p. 161-197.

${ }^{13}$ LACLAU, 1990, op. cit.

${ }^{14}$ TRINDADE, Hélgio. Construção da cidadania e representação política: lógica liberal e práxis autoritária. In: BAQUERO, Marcelo (org.). Cultura Política e democracia: os desafios das sociedades contemporâneas. Porto Alegre: EdUFRGS, 1994, p. 51.

${ }^{15}$ SANTOS, Wanderley Guilherme dos. A anomalia democrática: adolescência e romantismo na história política. Revista Brasileira de Ciências Sociais - RBCS, São Paulo, v. 13, n. 36, fev. 1998; GOHN, Maria da Glória. História dos movimentos e lutas sociais. São Paulo: Loyola, 2001.

${ }^{16}$ SEOANE, José; TADDEI, Emílio; ALGRANATI, Clara. The new configurations of popular movements in Latin America. In: BORON, Atilio A.; LECHINI, Gladys (ed.). Politics and social movements in a hegemonic world: lessons from Africa, Asia and Latin America. Buenos Aires: CLACSO, 2005.

${ }^{17}$ RANCIÈRE, Jacques. O desentendimento: política e filosofia. São Paulo: Ed. 34, 1996.

${ }^{18}$ IANNI, Octavio. Pensamento social no Brasil. Bauru, SP: Edusc, 2004; MARTINS, Paulo Henrique. Cultura autoritária e aventura da brasilidade. In: BURITY, J. (org.) Cultura e identidade: perspectivas interdisciplinares. Rio de Janeiro: DP\&A, 2002.
} 
dominantes, tal como defendem Alvarez, Dagnino e Escobar. ${ }^{19}$ Para que essas demandas se tornem objeto de discussão política, precisam, em certa medida, se tornar políticas e entrar no referido jogo. E nesse jogo, não são eles os "juízes", ou seja, não definem as regras. Nesse contexto, as lutas dos movimentos sociais têm sido guerras de interpretação, tentando colocar na agenda suas demandas e interpretações sobre justiça, cidadania e democracia, tendo como pano de fundo uma cultura política autoritária que, inclusive, perpassa suas próprias identidades, fazendo com que incorporem parte dos valores com os quais desejam antagonizar (tais como clientelismo, autoritarismo), como mostram as pesquisas. ${ }^{20}$ Resta saber como têm se dado essas guerras de interpretação no Conselho das Cidades.

\section{O PT, O GOVERNO LULA E A PARTICIPAÇÃO}

A atuação dos movimentos populares no governo Lula possuiu peculiaridades, uma vez que na sua fundação, nos anos 1980, o PT (Partido dos Trabalhadores) pretendia ser o catalisador dos movimentos. ${ }^{21}$ Mas desde o início, essa dimensão da identidade do PT era, em certo sentido, barrada pela lógica instrumental da política. ${ }^{22}$ Assim, os grupos hegemônicos no partido incorporaram a lógica das disputas eleitorais (internas e externas) ou a luta pelo lugar do poder (com menos espaço para a dimensão da utopia, da formação política e da transformação gradual). As vitórias eleitorais foram criando outro tipo de articulação e outros discursos (no parlamento e no executivo). A articulação entre lideranças dos movimentos (filiadas ao PT) e o parlamento fez dos parlamentares do PT os mediadores das demandas daqueles. Sobre esse aspecto, Laclau ${ }^{23}$ afirma que os discursos vão mostrar suas ambiguidades quando se encarnam como parte do processo de representação nas democracias modernas. As experiências de governos de esquerda, entre eles o PT, enfrentam essas contradições, lidando com uma cultura política tradicional autoritária e a hegemonia do sistema capitalista.

A matriz discursiva que está na fundação do PT também permeia os movimentos, porque o partido deveria inicialmente representar os interesses das categorias sociais que o integravam, num contexto de fins de ditadura, em que a legislação ainda era um limite ao exercício da democracia. E a democracia era o horizonte mítico, que incluía "justiça social" e "participação da base". Os agentes aderiram ao novo partido em função da "possibilidade de implementação de políticas sociais, a partir da proposta programática em discussão". Assim,

\footnotetext{
${ }^{19}$ ALVARÉZ, Sônia; DAGNINO, Evelina; ESCOBAR, Arturo (org.) Cultura e política nos movimentos sociais latinoamericanos: novas leituras. Belo Horizonte: UFMG, 2000.

${ }^{20}$ CASTELLS, M. A questão urbana. São Paulo: Paz e Terra, 1983; SANTOS, Boaventura de Sousa; AVRITZER, Leonardo. Para ampliar o cânone democrático. In: SANTOS, Boaventura de Sousa (org.). Democratizar a democracia: os caminhos da democracia participativa. Rio de Janeiro: Civilização Brasileira, 2003; CROSS, Cecília e FREY, Ada. Movimientos Piqueteros y democracia em Argentina: um estúdio sobre la acción política de cuatro organizaciones en el período 2002-2004. Latitude, Maceió, EdUFAL, ano 1, n. 1, p. 83-102, 2007.

${ }^{21}$ RUSCHEINSKY, Aloísio. Movimento de moradia e partido dos trabalhadores. Tese (Doutorado em Ciência Política), Universidade de São Paulo, São Paulo, 1996, p. 34.

22 MOUfFE, Chantal. Politics and passions: the stakes of democracy. London: Centre for the Study of Democracy, 2002.

${ }^{23}$ LACLAU, 1990, op. cit.
} 
desde o início, o caráter pragmático também já estava presente. No documento de fundação do $\mathrm{PT}^{24}$ estava escrito que eram objetivos do partido: (1) "transformar a visão dominante da política como esfera de atividade reservada à elite; (2) inovar na cultura política e implementar uma nova concepção de democracia a partir da base", com "democratização real das instituições de representação e da própria sociedade, onde o poder tenha caráter democrático e de natureza popular"; (3) procurar romper com "a postura paternalista sobre a classe trabalhadora", criticando a "tradicional delegação de poderes e de soberania contida na proposta liberal", bem como prometendo "rejeitar soluções de cúpula", através dos núcleos de base. Assim, no momento de seu nascimento, o PT se apresentava como o "braço institucional dos movimentos sociais, um instrumento de articulação e ao mesmo tempo de mediação para negociação dos direitos no parlamento". ${ }^{25}$ Mas a lógica das eleições predominou.

Para Gabriel Feltran, ${ }^{26}$ desde a sua fundação nos anos 1980, o PT apostou na construção de um projeto "democrático popular" que instituísse uma cultura política democrática, opondo-se ao autoritarismo tradicional; mas para Feltran, pelo menos três interpretações desse projeto coexistiam e estavam em disputa. O projeto mais amplo incluía a criação de canais de ativa participação da sociedade civil na gestão, possibilitando influenciar a definição do funcionamento do Estado, ou seja, a criação de conselhos. Estes representariam os canais que possibilitam a participação popular e os caminhos necessários (e possíveis) para a transformação social. A primeira interpretação (minoritária) aposta na relação entre Estado e sociedade a partir de parâmetros públicos (republicanos), elaborados para garantir os direitos e construir as políticas públicas com efetiva participação popular e como forma de superar as desigualdades sociais, para a construção do poder popular. ${ }^{27}$

Existem outras duas concepções que foram dominantes no governo Lula: uma defendia a "interface entre mercado e Estado também no que se refere à garantia de direitos e cidadania", em que as empresas poderiam ser fundamentais no financiamento das políticas públicas (diante da constatação de que o Estado está falido para os investimentos). Nesse discurso, há uma perda da "capacidade de pensar o mundo público como garantia de direitos e cidadania". ${ }^{28} \mathrm{Um}$ terceiro discurso substituiu crescimento econômico por desenvolvimento social que somente é possivel pela criação de consensos na relação "necessária" entre Estado, mercado e sociedade civil, incluindo amplamente o terceiro setor, braço social das empresas. Esse terceiro setor é que enfrentaria os problemas da pobreza, instituindo o desenvolvimento social. Essas três concepções possuem em comum a aposta na luta institucional como forma de construção da democracia (e como possibilidade de

\footnotetext{
${ }^{24}$ RUSCHEINSKY, op. cit., p. 106.

${ }^{25}$ Idem, ibidem, p. 112.

${ }^{26}$ FELTRAN, Gabriel de Santis. Deslocamentos - trajetórias individuais, relações entre sociedade civil e Estado no Brasil. In: DAGNINO, Evelina; OLVERA, Alberto J.; PANFICHI, Aldo (org.). A disputa pela construção democrática na América Latina. Campinas, SP: Unicamp: São Paulo: Paz e Terra, 2006, p. 373.

${ }^{27}$ Idem, ibidem, p. 407 (grifos no original).

${ }^{28}$ Idem, ibidem, p. 409.
} 
superação das desigualdades), sobretudo, a partir da existência dos espaços institucionais, como os conselhos e conferências.

Seguindo esse projeto político, a gestão de Lula investiu na criação de novos Conselhos Nacionais para atuar no controle e na definição das políticas sociais. Entre 2003 e 2006, foram criados 11 conselhos (formados por representantes da sociedade civil e do governo, totalizando 40 conselhos); em janeiro de 2007, foram realizadas diversas conferências. Em linhas gerais, o discurso que permeou o governo e, sobretudo, os militantes do PT, foi o da crença na instituição de um "novo contrato social", com bases republicanas, através da busca de consenso entre os agentes envolvidos nas políticas. Discurso também incorporado pelas lideranças dos movimentos populares.

Por outro lado, o governo foi criticado por dar continuidade à política econômica. ${ }^{29}$ Para Francisco Oliveira, ${ }^{30}$ a prioridade do governo era atender aos interesses do capital estrangeiro, e as políticas sociais apenas expressavam um "populismo emergente", provocando uma paralisação dos movimentos por causar perplexidade em antigos aliados e opositores. Boito Jr acredita que o investimento em políticas sociais representa uma nova fase do capitalismo mundial na qual tais políticas são incentivadas. ${ }^{31}$

Em nossa pesquisa, vimos que uma parcela dos membros dos movimentos sociais estava confusa quanto a sua relação com o governo (às vezes, tido como aliado; outras, como opositor). Tal visão ambígua se devia ao fato de a gestão de Lula ter sido marcada por ambiguidades e contradições, tentando conciliar interesses às vezes opostos. $E$ ao tomar decisões, oscilou entre medidas de "redistribuição de renda" e o atendimento às demandas empresariais. Sendo assim, as relações com o Congresso Nacional (os partidos), empresários e outros sujeitos presentes no jogo político impediram que o governo fosse fiel apenas aos anseios dos movimentos sociais.

Na definição de Laclau, $^{32}$ a representação de diferentes vontades se dá de modo precário. O terreno das vontades políticas, segundo o autor, não é só de transmissão de vontade, exige processos constantes de negociação e articulação com diversos sujeitos políticos e seus interesses. $E$ as relações de poder limitam o momento de decisão, que não pode ser fixado apenas num mecanismo racional. A lógica da hegemonia opera de maneira decisiva nessas oscilações, nas quais a adoção de medidas passa pelo convencimento das bases; e o governo de Lula conseguiu convencer a maioria dos eleitores de que as medidas

\footnotetext{
${ }^{29}$ Ao assumir o governo, a primeira decepção para os movimentos e sinal verde para empresários nacionais (conservadores) e investidores externos foi a "reforma da previdência", dando um tom moderador ao governo, ganhando a "confiança" desses setores. Segundo Leda Paulani, Brasil delivery: a política econômica do governo Lula. Revista de Economia Política, São Paulo, v. 23, n. 4, p. 58-73, out.-dez. 2003, p. 62, a reforma fazia parte de um acordo com o FMI, assinado em 2002. O programa Fome Zero também foi lançado para reforçar o lado social do governo, mas com ares de assistencialismo (Tavares, s/d). BOITO Jr, Armando. As relações de classe na nova fase do neoliberalismo no Brasil. In: CAETANO, Gerardo (Coord). Sujetos sociales y nuevas formas de protesta en La historia reciente de America Latina. Buenos Aires: CLACSO, 2006; PAULANI, Leda Maria, op. cit.

${ }^{30}$ OLIVEIRA, Francisco de. À sombra do Manifesto Comunista: globalização e reforma do Estado na América Latina. In: SADER, Emir; GENTILI, Pablo (orgs.). Pós-neoliberalismo II: Que Estado para que democracia? Petrópolis: Vozes, 1999.

${ }^{31}$ BOITO Jr, op. cit., p. 30.

32 1996, op. cit.
} 
adotadas representavam o caminho possível para a diminuição das desigualdades (e o desenvolvimento econômico). Além disso, nessa conjuntura, a "ordem social" não foi mantida à custa da repressão dos movimentos, como ocorreu em governos anteriores. A tônica foi a "negociação" com os movimentos, o que poderia ser traduzido como uma visão idílica do lema "ordem e progresso".

De acordo com as observações da pesquisa, as práticas discursivas no Conselho das Cidades foram permeadas pelo discurso que estava na origem do PT - como vimos anteriormente, o discurso "democrático", que se pautava pela necessidade de criação de espaços de negociação entre os diversos setores da sociedade, para criar instâncias em que os conflitos pudessem ser resolvidos de forma democrática e, de alguma forma, acreditando no convencimento dos empresários quanto às demandas populares. Negociação adquire um sentido de criação de espaços públicos para a "construção de consensos" ${ }^{33}$; os espaços são as conferências e os conselhos. Poderíamos dizer que essa crença nos conselhos paira no imaginário de membros dos movimentos (por nós observados), representando a possibilidade de participação no mundo da política, o espaço de legitimidade que não está garantido através da institucionalização da democracia procedimental.

No discurso de Tarso Genro, esse processo foi denominado de "novo contrato social". Assim, esse "espírito" (ou ethos) de busca de consenso se consolidou na gestão de Lula. O sentido era de construção de uma "gestão republicana e participativa", em que houvesse "compartilhamento de poder e corresponsabilidade entre o Estado e a sociedade civil", "diálogo de forma organizada, pública e transparente. Para os agentes dos movimentos, esse discurso se opunha às políticas setorizadas e clientelistas.

Para Boito $\mathrm{Jr}^{34}{ }^{34}$ esse é o discurso da articulação sindical ${ }^{35}$, tendência que tem dominado a CUT nos últimos anos. Esses significantes foram usados por diversos sujeitos, desde o Banco Mundial, até os movimentos sociais, com diferentes sentidos ${ }^{36}$ e incluíam o projeto de Bresser Pereira (2006), de um Estado republicano e democrático (com garantia de mercados competitivos e participação da sociedade civil). De um lado, uma concepção ingênua e simplista do consenso idealizado, sempre na figura da "negociação". Por outro, houve um esforço desmedido para criar aliados e garantir a governabilidade. Essa negociação idealizada escondia a fraqueza do governo frente ao empresariado, nacional e internacional. $O$ consenso em torno das negociações estaria na proliferação de espaços públicos.

\footnotetext{
${ }^{33}$ Segundo DRUCK, Graça. Os sindicatos, os movimentos sociais e o governo Lula: cooptação e resistência. OSAL - Observatório Social da America Latina, Buenos Aires, ano 6, n. 19, jul. 2006. Disponível em $<$ http://bibliotecavirtual.clacso.org.br.ar/ar/libros/osal19/debatesdruck.pdf>. Acesso em 02/05/2008, negociação foi o eixo da discussão da reforma sindical no Fórum Nacional do Trabalho, mas as propostas contrárias ao discurso das centrais não foram incorporadas ao documento.

${ }^{34}$ Op. cit.

${ }^{35}$ Boito Jr faz uma análise do discurso dos sindicalistas do ABC, em suas mudanças. Segundo ele, há uma identificação com o "estado de bem-estar social" na década de 1980. No início das lutas (anos 1970) e nos anos 1990 houve predominância de economicismo, dispensando o Estado e os direitos adquiridos, com ênfase na negociação coletiva e na ilusão da democracia dos fundos de pensão.

${ }^{36}$ Idem, ibidem; MARICATO, E. Os Ministérios das Cidades e a política urbana no Brasil. Arquitetura e Urbanismo, v. 156, p. 64-65, 2007.
} 
Os agentes dos movimentos de luta por moradia que entrevistamos interpretavam o momento do governo Lula como uma oportunidade política mais favorável à negociação e à implementação de seus projetos. Em nossa perspectiva, as negociações estão envolvidas em relações de poder, antagonismos e contingências, por isso, a participação se torna uma espécie de fetiche institucional, no sentido defendido por Gramsci, pois quando se trata de mudança estrutural, ou mesmo de matéria atinente a amplos grupos sociais de trabalhadores de diversas categorias, simplesmente não há negociação.

Sendo assim, negociação é um significante que se esvazia em seu sentido, pois pode representar a face democrática do governo, uma visão ingênua ou pode ainda ser vista como a possibilidade de construção de "parcerias" entre setores públicos e privados, para implementação das políticas públicas. ${ }^{37}$ Em alguns momentos, tem semelhanças com a lógica do mundo sindical, pois, como afirma Francisco Oliveira, ${ }^{38}$ é uma espécie de "transferência para o âmbito do governo" de "práticas de negociações sindicais, responsáveis - pensava-o Lula e muitos comentaristas e analistas do movimento sindical pelos melhores êxitos do novo sindicalismo", do qual Lula foi "o mais marcante líder". ${ }^{39}$ É uma visão idílico-positiva da "negociação". Concordamos com Oliveira que as negociações são marcadas pela hegemonia, ${ }^{40}$ mas reconhecemos que as políticas sociais resultantes desses contraditórios processos acabaram por trazer mais benefícios, em termos de justiça social, do que os governos neoliberais até então o fizeram. ${ }^{41}$

A questão em disputa é que essa aposta democrática inclui diferentes concepções. No discurso de alguns, "visa à construção de políticas nacionais e em longo prazo, políticas de Estado ao invés de políticas de governo" (fala literal da Secretária Nacional de Habitação da época e que se repete nas falas de muitos agentes). Busca de um consenso, mesmo com ambiguidades, pode ser lida como uma mudança no patamar da cultura política tradicional. Na fala do presidente Lula na Conferência das Cidades, em 2007, ficou claro que a pressão dos movimentos fazia o governo mudar sua postura, mas a negociação é que tornava a política factível. Na prática, o jogo político é mais complexo. De alguma forma, trata-se da construção de um poder público mais democrático do que os parâmetros inscritos na cultura política tradicional de aversão e repressão sistemática aos movimentos sociais. ${ }^{42}$

Os agentes dos movimentos sociais afirmaram que esse era um caminho importante para a gestão da coisa pública com vistas à criação de parâmetros universais, nos quais a linguagem dos direitos se sedimentasse na cultura política. Em certo sentido, as conferências criaram um espaço público de debates e possibilidades de proposições, como

\footnotetext{
${ }^{37}$ LACLAU, E. Glimpsing the future. In: CRITCHLEY, Simon; MARCHART, Oliver (ed.). Laclau: a critical reader. London: Routledge, 2006.

${ }^{38}$ OLIVEIRA, F. O momento Lênin. Novos Estudos, São Paulo, n. 75, p. 23-47, jul. 2006, p. 31.

${ }^{39}$ Idem, ibidem, loc. cit.

${ }^{40}$ LACLAU, Ernesto; MOUFFE, Chantal, op. cit.

${ }^{41}$ ANDERSON, Perry. Balanço do neoliberalismo. In: SADER, Emir e GENTILI, Pablo (orgs.). Pós-neoliberalismo: As políticas sociais e o Estado democrático. Rio de Janeiro, Paz e Terra, 1995; OLIVERA, F., 1999, op. cit.

${ }^{42} \mathrm{GOHN}$, Maria da Glória, op. cit.
} 
bem observou Dagnino. ${ }^{43}$ Para os agentes dos movimentos, houve uma mudança qualitativa importante: "reconhecimento e autonomia na relação com as agências estatais" (trecho da fala de uma liderança). A criação dos conselhos tornou os agentes dos movimentos representantes legítimos das demandas na cena política. Essa representação foi, muitas vezes, mais reconhecida pelo atual governo federal do que pelas gestões estaduais e municipais, sobretudo por conta da presença dos elementos da identidade "petista" já referida.

\section{CONSELHO DAS CIDADES: O JOGO DAS SEMI-IDENTIDADES}

Antes da análise do Conselho das Cidades, é preciso informar que, durante o governo de Fernando Henrique, foi aprovado o Estatuto das Cidades ${ }^{44}$ e instituído o Conselho Nacional de Desenvolvimento Urbano (CNDU); a política era gerenciada pela Secretaria Especial de Desenvolvimento Urbano da Presidência de República. O referido Conselho foi instituído mediante medida provisória em 2001. Na letra da lei, o CNDU era um órgão deliberativo e consultivo integrante da estrutura da Presidência da República. Tinha a função de propor diretrizes, acompanhar e avaliar a política nacional de desenvolvimento urbano, que não existia no referido período. A composição era dúbia. 0 artigo 11 da medida provisória indicava que o CNDU era "composto por seu Presidente, pelo Plenário e por uma Secretaria-Executiva, cujas atribuições seriam definidas em decreto". O artigo 12 complementava: "O Presidente da República disporá sobre a estrutura do CNDU, a composição do seu plenário e a designação dos membros e suplentes do Conselho e dos seus comitês técnicos". O Conselho foi criado por ser uma exigência do Estatuto das Cidades. Assim, o governo criou o CNDU em moldes autoritários. Nesse caso, vemos claramente a postura de um governo centralizador, com a concepção de conselho a partir da decisão do governante. O CNDU é um bom exemplo de que a criação de um conselho não significa necessariamente a participação da sociedade civil.

Antes da criação do Conselho das Cidades, houve o processo de articulação dos movimentos que possibilitou a criação do Ministério das Cidades, no início do governo Lula (2003). Representou uma inovação, já que, nas gestões anteriores, a política urbana era pensada de forma dissociada. ${ }^{45} \mathrm{~A}$ política de moradia popular esteve associada à política de assistência social. Com essa mudança institucional, foram colocados na agenda política

\footnotetext{
${ }^{43}$ DAGNINO, Evelina. Sociedade civil e espaços públicos no Brasil. In: DAGNINO, Evelina (org.). Sociedade civil e espaços públicos no Brasil. Rio de Janeiro: Paz e Terra, 2002.

${ }^{44} \mathrm{O}$ Estatuto das Cidades é o nome dado a um conjunto de leis que tratam da política urbana, envolvendo também a criação de uma gestão participativa (conselhos estaduais, municipais e o conselho nacional). A proposta passou dez anos no Congresso Nacional e foi aprovada no governo Fernando Henrique Cardoso. CARVALHO, Ana Paula Soares. Reforma urbana no Brasil: a intelligentzia e o Estatuto da Cidade. In: Anais do 13 Congresso Brasileiro de Sociologia. Recife: UFPE: Grupo de Trabalho "Cidades e Processos Sociais", 2007. Mimeografado.

45 SANTOS, Cláudio Hamilton. Políticas federais de habitação no Brasil: 1964/1998. Brasília: Rio de Janeiro: IPEA, 1999. (Texto para discussão, n. 654). Disponível em <http:www.ipea.gov.br>. Acesso em 20 mar. 2008; LORENZETTI, Maria Sílvia Barros. A questão habitacional no Brasil. Brasília, DF: Câmara dos Deputados, jul. 2001.
} 
temas como reforma urbana, articulados à política habitacional e à política de desenvolvimento urbano. $O$ processo de criação do Ministério teve participação crucial dos sujeitos (movimentos e entidades) que compuseram o Fórum Nacional de Reforma Urbana. A proposta incluía a criação de um Conselho para influenciar a política urbana.

Vale ressaltar que, inicialmente, o Ministério esteve sob a gestão do petista Olívio Dutra, com assessoria de intelectuais petistas; ele foi substituído por Márcio Fortes, indicado por um partido de direita, mas que estava na base aliada. Esse é um dos exemplos das negociações e ambiguidades presentes ao longo do governo Lula.

O Conselho das Cidades, criado em 2004, já era composto por representantes eleitos em Conferências Nacionais. ${ }^{46}$ A composição desses espaços de representação englobou os diversos segmentos envolvidos na discussão do desenvolvimento urbano, desde o poder público à sociedade civil, incluindo os empresários. Do que propuseram as referidas Conferências, as únicas cláusulas não incorporadas ao texto foram a da participação paritária entre homens e mulheres e a da representação étnico-racial. A composição inicial foi alterada de acordo com proposta aprovada na $2^{a}$ a Conferência Nacional, em 2005, ficando com a seguinte representação:

16 membros titulares e respectivos suplentes do Poder Público Federal;

9 membros do Poder Público Estadual, com suplentes (no Conselho anterior, eram 27);

12 membros do Poder Público Municipal, com suplentes;

23 membros do Movimento Popular, com suplentes;

8 membros de entidades dos trabalhadores, com suplentes;

8 membros de entidades empresariais, com suplentes;

6 de entidades acadêmicas e de pesquisa, com suplentes;

4 de ONGs (com suplentes)

Uma das atribuições mais contraditórias determina que o Presidente do Conselho seja o próprio Ministro, que exerce o poder do voto de qualidade em caso de empate (vale ressaltar que nem todos os conselhos nacionais funcionam assim). Em caso de votação, as deliberações são feitas mediante aprovação de maioria simples. A participação no Conselho não é remunerada, e a infraestrutura é parte da previsão orçamentária do Ministério. Tanto o Conselho Nacional quanto os estaduais e os municipais devem ser presididos pelos representantes do Poder Executivo em questão. Assim, ficam à mercê dos gestores e suas concepções de democracia. Em alguns casos, os conselhos só existem formalmente, mas não funcionam.

\footnotetext{
${ }^{46}$ As Conferências Nacionais funcionam como congressos sindicais em que há delegados (representantes) eleitos e indicados. Os representantes foram eleitos em Conferências Municipais e Estaduais, de acordo com os segmentos. As propostas foram feitas nos municípios e estados e levadas às Conferências Nacionais, que funcionam com cerca de dois mil participantes, em decisões em grupos temáticos e uma grande plenária, como uma grande cena política. RODRIGUES, Cibele. Cultura política e Movimentos Sem-Teto: as lutas possíveis. 2009. 364 f. Tese (Doutorado), Universidade Federal de Pernambuco, CFCH, Sociologia, Recife, 2009
} 
No Conselho Nacional, participam apenas os quatro movimentos que possuem representação nacional: Movimento Nacional de Luta por Moradia (MNLM), União Nacional de Moradia Popular (UNMP), Central de Movimentos Populares (CMP) e Confederação Nacional de Associações de Moradores (CONAM). Excetuando-se a CONAM, os demais são liderados por militantes petistas. Esses movimentos, ao longo da década de 1980, se articularam em torno do Fórum Nacional de Reforma Urbana (FNRU), como afirma uma liderança: "Os movimentos sociais, eles participam dentro de uma rede de movimentos, chamado Fórum Nacional de Reforma Urbana. E nesse fórum nós temos proposto resoluções importantes no âmbito do conselho nacional das cidades". É um exemplo de movimento surgido da criação de direitos, ${ }^{47}$ o que representa uma mudança em relação ao padrão populista. É visível a crença de que esse tipo de participação pode mudar a cultura política ao romper com a fragmentação, desarticulação e exclusão das políticas urbanas anteriores.

O discurso das entidades reunidas no FNRU pode ser resumido assim: a crença no Conselho é a crença na "parceria entre sociedade e poder público" para a busca de soluções efetivas para os problemas das cidades, que mudem de fato a vida das pessoas, sobretudo as excluídas da cidadania, sem acesso a direitos mínimos. ${ }^{48}$ Nesse caso, há uma coincidência entre o que pregam os movimentos e o que estava no discurso oficial do governo: "a participação na elaboração das políticas é um direito dos cidadãos". Qualquer "demanda" é a exposição de um dano (uma lacuna) e se constitui como objeto político; então, como afirma Pickvance, ${ }^{49}$ não há como distinguir demandas materiais e demandas políticas. Na cena pública, todas são demandas políticas. De uma forma geral, o Conselho tem discutido questões importantes que interferem na estrutura da política urbana, em termos de legislação, programas e orçamento..$^{50} \mathrm{O}$ Conselho apenas indica e discute o orçamento, mas não decide, e suas indicações não são, necessariamente, respeitadas.

Podemos considerar uma mudança no patamar da discussão, pois antes, nem o debate existia. Nesse espaço, os agentes das redes movimentalistas aproveitaram o espaço para denunciar as ambiguidades do governo Lula. Por exemplo, foi confrontado o valor destinado ao superávit primário (R\$ 70 bilhões) com os valores destinados para habitação (R\$ 550 milhões em 2004; R\$ 767,5 milhões em 2005). Houve espaço para críticas e moções em relação a ações governamentais de órgãos como a Caixa. ${ }^{51}$ Mas não se produziram mudanças.

Uma das primeiras iniciativas no âmbito do Conselho foi a criação do Programa Crédito Solidário, que significava, para os agentes do FNRU, "o início de uma transição para

\footnotetext{
${ }^{47}$ MUTZENBERG, Remo. Ações coletivas, movimentos sociais: aderências, conflitos e antagonismo social. Tese (Doutorado Sociologia), Departamento de Ciências Sociais, Universidade Federal de Pernambuco, Recife, 2002.

${ }^{48}$ SILVA, Carla Almeida. Os fóruns temáticos da sociedade civil: um estudo sobre o fórum Nacional de Reforma Urbana. In: DAGNINO, Evelina (org.). Sociedade civil e espaços públicos no Brasil. São Paulo: Paz e Terra, 2002, p. 143-185.

${ }^{49}$ PICKVANCE, Chris. From urban social movements to urban movements. IJURR, v. 27, n. 1, p. 102-109, 2003.

${ }^{50}$ LOJKINE, J. O Estado capitalista e a questão urbana, São Paulo, Martins Fontes, 1981; CASTELLS, M., op. cit.

${ }^{51}$ BRASIL. Governo Federal. Ministério das Cidades. Secretaria-Executiva do Conselho das Cidades. Conselho das Cidades: um exercício de gestão democrática. Brasília: Imprensa Oficial, 2005.
} 
uma nova formar de propor a política habitacional articulada com a política urbana". ${ }^{52}$ Naquela ocasião, foi considerada a "primeira política habitacional com integração total ao tecido urbano e a um projeto de desenvolvimento urbano includente", segundo fala de Raquel Rolnik, registrada na Ata da 4a Reunião do Conselho das Cidades ${ }^{53}$ - mesmo que esbarrando na burocracia ${ }^{54}$ e nos despejos da Caixa, denunciados nas reuniões do Conselho.

Naquele momento, se o governo estava em disputa, o Conselho era o lugar da resistência. E a luta no Congresso ainda era outro campo de disputa. Nesse contexto, o discurso estava centrado na mudança da cultura política, em que se constatava o problema da participação política insuficiente. Além disso, outro problema era o fato de a "política urbana" ter sido tratada "de forma fragmentada, clientelista e excludente". Os sentidos foram articulados na necessidade de uma Política Nacional de Desenvolvimento Urbano ${ }^{55}$. Mas essas soluções, por mais que parecessem universais, esbarravam em problemas situados para além da política urbana em si. Por exemplo, na sexta reunião do Conselho (junho de 2005), foi apontado um problema: pensar em desenvolvimento urbano deveria supor pensar num projeto nacional de desenvolvimento econômico. Jean Bitoun, importante geógrafo convidado para discutir as questões de desenvolvimento questionava: se a política urbana vai para um lado e a gestão para outro, vai haver complicações. Esse debate apareceu de outra forma na primeira reunião, quando o representante do Ministério da Fazenda reconstituiu todo o discurso neoliberal que barrava o aumento de recursos para uma política desenvolvimentista. Também entra em desacordo quando os movimentos se colocam contra a "restrição da participação do setor privado no investimento em transporte e saneamento, por meio de PPP ou concessão de serviços". ${ }^{56}$ Com o passar do tempo, o governo Lula conciliou, em termos, as duas coisas. Aprovou as Parcerias Público-Privadas (para o saneamento) e aumentou de forma paulatina os recursos para a política urbana. As parcerias não foram propostas pelos movimentos, mas também não houve rejeição por parte deles na Conferência Nacional realizada em 2007.

Outro exemplo vem da aposta na aprovação de marcos regulatórios importantes para criação de uma política de Estado. Algumas dessas propostas já vinham sendo discutidas pelas entidades componentes do FNRU, desde a década de 1980. Podemos avaliar a dificuldade de operacionalização das propostas a partir da discussão sobre o FNHIS/SNHIS (Fundo e Sistema Nacional de Habitação de Interesse Social), que demorou quase três anos para ser regulamentado. O SNHIS/FNHIS foi "fruto de um projeto de lei de iniciativa popular, apresentado pelas entidades dos movimentos de moradia, que, após

\footnotetext{
${ }^{52}$ Idem, ibidem.

53 Idem, ibidem.

${ }^{54}$ Nessa reunião, foi divulgado um levantamento do Ministério, segundo o qual havia 128 passos para uma obra ser realizada. E um dos principais problemas da política urbana foi a falta de definição das responsabilidades dos entes federativos.

55 Nesse sentido, o Conselho publicou quatro Resoluções (a 13, supracitada; a 23, de 09/12/2004; 25, de 18/03/2005; 34 de 18/03/2005). A primeira tinha por fim propor diretrizes para criação dos conselhos (estaduais e municipais), bem como fazer um levantamento dos conselhos existentes. Insistia na importância da participação, da democracia e no respeito às resoluções das Conferências Nacionais e à autonomia dos Conselhos (locais), bem como na garantia de orçamento e instituição de suas secretarias executivas.

${ }^{56}$ Idem, ibidem.
} 
tramitar 13 anos, foi sancionado pelo Presidente da República em 2005". 57 "O objetivo da lei é subsidiar a urbanização de assentamentos precários e construção de moradias para a baixa renda ${ }^{58}$ através da transferência de fundo a fundo, sempre que estados e municípios instituam seus fundos, políticas e conselhos de habitação". ${ }^{59}$ O SNHIS inclui ainda a obrigatoriedade de criação dos Conselhos e Fundos para estados e municípios que queiram aderir ao sistema.

A primeira decepção veio com o corte no orçamento do FNHIS. Em 2006, foram lançadas duas resoluções que atendiam a demandas de empresários do setor imobiliário; ao mesmo tempo, o Projeto de Lei Orçamentária diminuiu pela metade os recursos do FNHIS, não considerando as resoluções do Conselho das Cidades. O FNRU divulgou uma nota de repúdio, na qual solicitava uma reunião com os ministérios envolvidos e a presidência.

Mesmo diante de tal "repúdio", os dados do próprio governo confirmam que nada se modificou. Em 2006, foi executado R\$ 1 bilhão, e em 2007, foi “reduzido para R\$ 458 milhões". ${ }^{60}$ O Fórum priorizava a atuação nos marcos da democracia participativa, elaborando propostas, mas também exigindo mudanças na crença que as deliberações coletivas seriam acatadas e as negociações possíveis; fez também uma crítica à priorizaçao do capital imobiliário. Mesmo assim, o FNRU segue criando uma discussão pública sobre as questões da política nacional de desenvolvimento urbano, e sua atuação tem uma repercussão molecular, ainda não totalmente perceptível, mas já reconhecida, sobretudo no tocante ao maior respeito na relação entre movimentos populares e governo.

Para esses agentes, a construção da democracia consiste não apenas em instituições formais, mas na inclusão da participação, centrada nesse modelo de conselhos e de conferências enquanto espaços públicos de deliberação. Então, a proposta dos conselhos é vista como forma de ampliar a participação e a interferência de outros sujeitos que não apenas os eleitos para a representação legislativa formal. E os representantes dos movimentos percebem que não basta instituir conselhos e conferências, mas também criar uma "cultura democrática e participativa", como consta na resolução do Conselho, em seu Art. 1ำ, Inciso I, Resolução 13 , de 16/06/2004, ${ }^{11}$ ou ainda, uma "cultura de participação popular e gestão democrática das políticas". Repete-se, assim, o discurso de criação do PT, no qual se constata que não há participação política. Esse princípio está relacionado com a crença nas conferências e nos conselhos como espaços por excelência da democracia, compreendida como a "possibilidade de negociação e articulação da pluralidade de interesses na construção de políticas nacionais" A cadeia de significados inclui ainda uma perspectiva de ação "propositiva", com qualidade técnica para construir a política urbana.

Esse é o conjunto de significantes que está no discurso dos representantes mais envolvidos com a luta política. Em sua recomendação aos sujeitos sociais e governos (estaduais e municipais), a prioridade é a criação dos conselhos (estaduais e municipais)

\footnotetext{
${ }^{57}$ MINISTÉRIO DAS CIDADES. Exercício de gestão democrática. Brasília, 2007, p. 9.

${ }^{58}$ Definiu-se baixa renda como o ganho mensal de até cinco salários mínimos.

${ }^{59}$ Idem, ibidem, loc. cit.

${ }^{60}$ IPEA, 2007, p. 283.

${ }^{61}$ BRASIL, op. cit.
} 
para tentar expandir o discurso de "construção da política urbana com participação" incluindo a justiça social; ou seja, a política urbana deve ter como objetivo "reverter a desigualdade existente nas cidades". Mas se debate com um dilema: somente com a política urbana, como será possível?

\section{PARTICIPAÇÃO, JOGO DE SEMI-IDENTIDADES E RECONHECIMENTO}

O que de fato o Conselho das Cidades ampliou foi a relação direta entre os representantes dos movimentos que o compõem e o governo federal, sobretudo o Ministério, mas também, uma possibilidade de interlocução direta com o poder público em seu âmbito federal. As redes movimentalistas da reforma urbana apostaram no governo Lula como possibilidade concreta de implementar esse programa, mesmo que tenham tido constantes decepções. As lideranças eram filiadas ao PT e ao PCdoB, mas não exatamente nos moldes do sindicalismo "pelego". Seria muito simplista considerá-los subservientes ou correias de transmissão dos partidos, porque embora defendessem o governo, possuíam propostas e discordavam em vários pontos. Existia o reconhecimento de que foi aquele o governo que mais atendeu às suas reivindicações. Pela primeira vez, viram a intermediação direta entre movimentos populares e o governo federal, antes mediada por parlamentares. Essa relação tem sido importante para a aprovação de leis e a destinação de recursos para a política urbana.

A fala dos movimentos populares incluía a crítica ao governo, sempre destacando que as conquistas foram obtidas através de muita pressão. De uma forma mais específica, referiam-se à criação do Conselho das Cidades (ConCidades) como uma grande vitória dos movimentos, já que sempre foi uma proposta deles. Consideravam que o processo seria "lento e novo" para todos (movimentos e governo) e que nele, a crença baseava-se na construção de uma nova instituição (o Conselho) como instrumento para a criação de políticas de estado. Essa crença e a pauta de reivindicações dos movimentos foram frutos da construção coletiva no Fórum Nacional de Reforma Urbana ao longo de sua existência. ${ }^{62} \mathrm{De}$ forma geral, reconheciam aquele momento como a oportunidade para concretizar propostas antigas, materializar seus sonhos, gerando também muitas expectativas ${ }^{63}$. Por outro lado, as decepções foram muitas, como no caso dos Programas de Aceleração do Crescimento (PAC) e Minha Casa, Minha Vida, que não consideram as diretrizes aprovadas

\footnotetext{
${ }^{62}$ CARVALHO, Ana Paula Soares, op. cit.

${ }^{63}$ Uma grande bandeira da Conferência (2007) era fazer o Conselho se transformar em um espaço deliberativo. Essa discussão já tinha sido aprovada desde a primeira reunião (2004), mas não logrou êxito. As lideranças compreendem que se trata de um processo educativo, ainda em construção. E, para alguns, era um momento em que se devia privilegiar o diálogo. Eles conseguiram avaliar que, tanto o Conselho quanto as conferências eram a objetivação do "controle social" (nos termos deles). Nesse sentido, é positivo o fato da coordenação da 3a Conferência ter sido feita pelo Conselho. Outro militante mais otimista cria que o governo tinha acatado os pactos do Conselho, o que corresponde, mas, em certa medida. Ainda persiste a desconfiança quanto à burocracia e as dificuldades de se implementar as leis. Opiniões divergentes também no campo movimentalista.
} 
no Conselho e presentes no Estatuto das Cidades, em termos de legislação ambiental e controle social das obras.

Sendo assim, em seu discurso, o Conselho é concebido como o espaço das disputas, um ente com "uma grande capacidade de pressão sobre o ministério e o governo" e tem, dessa maneira, "democratizado as políticas". O funcionamento do ConCidades é perpassado por uma guerra de interpretações, pela hegemonia, por ser composto por entidades diferenciadas, com posições divergentes e articulações constantes. É nesse sentido que essa participação pode ser um fetiche.

Em termos de votação, as entidades que pertencem ao Fórum Nacional de Reforma Urbana estão em maior número e votam "em bloco", mas isso não garante a aprovação irrestrita de todas as suas propostas. Como bem afirma uma liderança: "nós temos sempre a correlação de forças, também estabelecemos uma afinidade com os sindicatos dos trabalhadores, então, dificilmente a gente perde, podemos dizer assim, uma votação". Mesmo assim, eles necessitam ceder em algumas questões. Na avaliação do ministro das Cidades, a existência de várias posições no Conselho é parte do processo democrático: "quando não há consenso, se negocia. É assim mesmo. As partes vão chegando a um ponto de equilíbrio, em saber ceder sem perder os objetivos". Mas nem sempre é assim.

Nessa relação entre os diversos segmentos, todos os agentes têm modificado suas identidades. Enquanto o ministro teve de admitir publicamente a importância do Conselho e dos movimentos, também os empresários aderiram a esse discurso; embora saibamos que os sentidos são diferentes, isso já representa uma mudança. Mesmo que seja uma estratégia, força a tornar público o debate sobre as políticas. Nesse jogo de semiidentidades, ${ }^{64}$ também os movimentos têm incorporado a lógica do governo e buscado pactos com empresários. A busca pelos pactos e o jogo das identidades se materializou em um acordo proposto pelos empresários, gestado no Conselho e assinado na Conferência das Cidades (2007), que se transformou numa campanha unificada pelo direito à moradia (Campanha nacional Moradia Digna: uma prioridade social) incluindo as entidades envolvidas no ConCidades, sobretudo movimentos/ONGs e empresários.

Para os representantes dos movimentos, o pacto assinado na Conferência foi apontado como um tipo de "aliança tática", como um acordo entre sindicatos e patrões, reforçando o sentido de negociação (presente no governo Lula). Esses representantes comentaram que foram os empresários que os convidaram, para mostrar que estavam de acordo na postura de buscar mais financiamentos para a habitação. Mas ainda persistia uma desconfiança em relação aos empresários. Os representantes dos movimentos reconheciam que o fato novo era negociar com eles, pois estavam acostumados a negociar com o governo. Pareceu-nos uma aliança contraditória, pela qual buscaram uma justificativa racional, pois vislumbraram algum tipo de ganho comum, mesmo com intenções diferentes. Interpretavam o momento como uma chance de convencer os empresários que suas reivindicações eram justas e que eles poderiam tratar melhor os trabalhadores. ${ }^{65}$

\footnotetext{
${ }^{64}$ LACLAU, 1990, op. cit.

${ }^{65}$ RANCIÈRI, op. cit.
} 
Além da possibilidade de convencer os empresários quanto à importância das demandas dos movimentos (e dos sem-teto) de forma "universal", o pacto e a campanha foram simbolizados como uma ação tática, ao mesmo tempo em que inseria na agenda empresarial a "habitação popular", com reconhecimento das limitações dessa negociação (em certo sentido, ferindo os princípios da tradição dos movimentos em que interesses dos empresários são antagônicos aos interesses das classes populares):

\begin{abstract}
Nós temos um encontro de 3 dias em três e três meses, isso favoreceu evidentemente o diálogo, nós temos certeza: nós temos uma contradição ideológica, que só será vencida se a gente mudar o regime. Mas nós estamos nesse regime, nesse país, nesse momento histórico, capital e trabalho dificilmente vão encontrar lá na frente os mesmos objetivos. Agora pontualmente, nós temos 8 milhões de déficit de moradia, se a desoneração do produto pra fazer casa para moradia popular existir, tanto os empresários quanto a gente, vai ganhar e mais gente vai ter casa. Então isso é um tema pontual e nós sabemos disso, isso foi extremamente colocado desde a primeira conversa: nós não estamos aqui pra unificar a luta. Agora pontualmente nós podemos ter (...) a gente sabe que a sociedade é dividida em classes e a gente sabe nosso lugar. (liderança UNMP entrevistada na Conferência das Cidades de 2007.) (Grifos no original).
\end{abstract}

Esse é o jogo das semi-identidades a que nos referimos. Para eles, diante da grande dimensão da falta de moradia, valia a pena fazer alianças pontuais, que se traduziam em ganhos para ambos (empresários e movimentos), mas, sobretudo para as "classes populares", que, mesmo no processo de modernização capitalista brasileiro, não conseguiram ter acesso aos "bens mínimos" da promessa da cidade do capital. ${ }^{66}$

Nesse sentido, as lideranças dos movimentos estavam cientes da mudança de postura do governo, mas também dos seus limites. Percebiam a grande desigualdade social existente no país. Eles pareciam acreditar que havia uma possibilidade de envolvimento dos empresários para diminuição dessa desigualdade. As lideranças tinham o intuito de mostrar que poderiam lucrar atendendo às demandas populares - o que, antes, parecia incompatível com o modelo de urbanização e industrialização (em que os pobres não eram pensados enquanto cidadãos). Tanto as demandas populares quanto as demandas de movimentos sociais foram sempre vistas como "desordem", por políticos e empresários. Os direitos foram, em algum momento, simbolizados como excesso, e as manifestações, uma afronta. Essa concepção ainda está presente na má qualidade (e no pequeno tamanho) das unidades habitacionais construídas para os "pobres". ${ }^{67}$ No discurso de alguns empresários, engenheiros e políticos, qualquer tipo de moradia já é considerado "muito", segundo depoimentos de técnicos das prefeituras presentes na Conferência. Nesse sentido, foi possível observar uma mudança na linguagem e nas concepções de ambos na cena política. ${ }^{68}$

\footnotetext{
${ }^{66}$ FURTADO, Celso. Em busca de novo modelo: reflexões sobre a crise contemporânea. São Paulo: Paz e Terra, 2002; OLIVERA, F. Crítica à razão dualista: o ornitorrinco. São Paulo: Boitempo Editorial, 2003.

${ }^{67}$ Podemos, ainda, tomar como sintoma desse discurso os famosos projetos de geração de emprego e renda para os pobres: curso de corte e costura, pedreiro, culinária, cabeleireiro.

${ }^{68}$ RANCIÈRE, op. cit.
} 
Os movimentos têm representado a "voz" da população pobre nesse contexto perverso de desigualdades e autoritarismo. ${ }^{69}$ As lideranças agem como representantes, no sentido dado por Laclau, $^{70}$ que vão buscar articulações para atender às demandas particulares tornadas universais. Num horizonte de uma cultura política com requintes diferenciados de autoritarismo, o discurso desses agentes se articula em torno dos significantes: políticas públicas e direitos. Esses são possibilidades de uma revolução democrática (é como se fosse uma nova edição da Revolução Francesa, com mais de duzentos anos de atraso). Como disse um membro de uma ONG do FNRU: "sou a favor das reformas e, por isso mesmo, continuo revolucionário".

Nesse debate, os sentidos atribuídos ao que se pode chamar de políticas públicas são questionáveis. ${ }^{71} \mathrm{O}$ questionamento é sobre as possibilidades e as impossibilidades dessas ações de ONGs e movimentos para alargar as brechas em que agem, articulando vontades e ampliando o projeto e as demandas. A expansão dessa cadeia de demandas (inscritas numa superfície mítica) pode ser barrada pelo próprio tipo de demanda de habitação como aquisição de um bem e simbolizada como benesse por quem a recebe. Assim, há que se questionar a demanda em si e, sobretudo, a forma como as políticas se restringem a dar as casas.

Para sair do âmbito da assistência, o discurso do FNRU inclui política pública. Mas essa pode se tornar apenas um "projetinho", nos termos de Teixeira, ${ }^{72}$ como uma demanda isolada, podendo fazer parte de um projeto que possui outro direcionamento (diferente do desejado pelos agentes). Acreditamos que o problema é o teor limitado da demanda e a forma como foi sendo constituída a luta por moradia, tanto na memória coletiva das lutas sociais quanto no imaginário político.

De outro lado, mesmo que se amplie a discussão da política para política urbana, a parte de política que se torna um ato de "dar casas" é sempre assistencialista ou compensatória. Para "os revolucionários", essa luta economicista é uma etapa para a luta política. Mas como afirmou Luciana Tatagiba, o projeto de "democratização do Estado e da sociedade" não está bem delineado. Afinal, esses são significantes que deslizam na superfície mítica desses revolucionários que buscam a transformação. As mobilizações não são incompatíveis com negociações, numa "conjuntura favorável ao diálogo". A avaliação da atuação política tem como referência a memória construída no processo da Constituinte de 1987: "a política urbana brasileira é diferente de todas as outras políticas, a política urbana brasileira, toda ela, foram os movimentos urbanos que pautaram, foi assim quando em

\footnotetext{
${ }^{69}$ DOIMO, Ana Maria. Movimento popular no Brasil pós-70: formação de um campo ético-político. Tese (Doutorado em Ciência Política), Departamento de Ciência Política, Universidade de São Paulo, São Paulo, 1993; DAGNINO, Evelina; OLVERA, Alberto J.; PANFICHI, Aldo. Para uma outra leitura da disputa pela construção democrática na América Latina. In: DAGNINO, Evelina; OLVERA, Alberto J.; PANFICHI, Aldo (orgs.). A disputa pela construção democrática na América Latina. Campinas: Paz e Terra, 2006; TELLES, Vera da Silva. Direitos sociais: afinal do que se trata? Belo Horizonte: UFMG, 2006.

${ }^{70}$ LACLAU, 1996, op. cit.

${ }^{71}$ TEIXEIRA, Ana Cláudia. Identidades em construção. São Paulo: Annablume: FAPESP: Instituto Pólis, 2003, p. 36.

${ }^{72}$ Idem, ibidem.
} 
1987, a gente começou a colher assinaturas para a emenda dos capítulos 182 e 183 da política urbana" (grifos no original). Os agentes reconhecem sua participação no âmbito da construção das políticas: "essa política é fruto de toda uma luta dos movimentos sociais, por isso que é uma luta, por isso que é uma política que tem uma efetiva participação dos movimentos sociais, porque ela é fruto de toda uma luta dos movimentos sociais". (grifos no original).

Entretanto, há uma grande contradição, como destaca Raquel Rolnik: "73 "no campo institucional e legal, nós somos um exemplo" para o resto do mundo, já que "o direito à moradia está escrito em nossa Constituição, nós temos o Estatuto das Cidades e temos também o sistema de habitação de interesse social" Mas o

grande desafio é implementação, implementação, implementação... A singularidade do Brasil que chama a atenção de vários países do mundo é o fato de que todo esse processo de constituição institucional foi feito com muita participação popular. Nós somos uma referência para o mundo. (2007).

Para Maricato, ${ }^{74}$ as mudanças ocorridas em decorrência da hegemonia neoliberal e "os cortes nas políticas de transporte, habitação e saneamento" tiveram consequências desastrosas para as cidades. Para ela, os movimentos urbanos estão passando por uma fase de "atração muito forte pelo espaço institucional ou pela institucionalização de práticas participativas, como se isso constituísse um fim em si". Mesmo considerando a importância do controle social enquanto espaço de aprendizado e de ampliação de conquistas por demandas sociais, é possível perceber que o Estado possui um imenso poder de cooptação e corrupção, sobretudo "numa sociedade como a nossa: patrimonialista e desigual". A prova disso é "o rumo seguido em anos recentes pelo Partido dos Trabalhadores, quase restrito à prática eleitoral e institucional" Por isso, podemos falar em fetichização do processo de participação.

\section{CONSIDERAÇÕES FINAIS}

Avaliamos que tem havido inclusão de algumas demandas dos movimentos na agenda política, e parcelas de empresários e políticos passam a aceitar as demandas dos movimentos populares como racionais e justas. A identidade de ambos tem se modificado, levando-os a se unirem para reivindicar do governo federal mais verbas para habitação popular. Ao mesmo tempo, a influência do Conselho das Cidades na definição do orçamento e no controle social de sua aplicação é limitada. Assim, concluímos que a simples existência de uma instância de controle social não garante a constituição de um poder popular; a participação é um elemento importante e tem gerado mudanças paulatinas, mas também pode levar ao fetiche dessa participação. Em outras palavras, a crença no poder dos

\footnotetext{
${ }^{73}$ ROLNIK, Raquel. Cidades: O Brasil e o Habitat II. Revista Teoria e debate, n. 32. julho/agosto/setembro de 1996. Disponível em:

<http://www2.fpa.org.br/portal/modules/news/article.php?storyid=2234>. Acesso em 20 de janeiro de 2007.

${ }^{74}$ Op. cit.
} 
conselhos faz com que haja um grande investimento nessa participação que, ao final, pode resultar em poucas mudanças.

No atual contexto, o discurso participativo representa uma mudança, mesmo considerando que os conselhos e as conferências não são as instâncias de decisão política, mas de construção coletiva de demandas que vão interpelar o "sistema político", com legitimidade, denunciando as contradições performáticas do Estado republicano. ${ }^{75}$ Assim, uma das mudanças no patamar da cultura política se dá no tratamento em relação aos movimentos. De alguma forma, criou-se uma brecha para uma disputa; antes, era repressão ou desprezo.

Por outro lado, há limitações, pois como bem apontou Marx, ${ }^{76}$ a luta pela emancipação é limitada, entre outras coisas, por interesses antagônicos. Em Marx, a emancipação política é a forma limitada da emancipação plena. No Brasil, a emancipação política não conseguiu se tornar significativa no imaginário político (cultura política), então, ela parece ser o impulso das lutas sociais para garantir patamares mínimos de direitos e cidadania ainda não efetivados. Mesmo que não se atinja a plenitude, está em questão, e o que parece mínimo tem dificuldades em se sedimentar, por conta do processo histórico que inscreveu traumas nas relações entre movimentos sociais e Estado/governo. $O$ jogo das relações sociais envolve agentes capitalistas, agentes governamentais e os agentes dos movimentos, cujas identidades são bloqueadas. A lógica da burguesia, que tem como interesse a acumulação de capital, barra os processos de emancipação; em outro sentido, as lutas sociais podem barrar a falta de limites de sua acumulação. E os agentes estatais podem oscilar em seus posicionamentos, buscando adesão popular e atendimento dos diversos interesses em jogo. O poder é sempre limitado pelas relações nas quais está inserido. Esse jogo é de grande instabilidade, e suas fronteiras são oscilantes. Os agentes dos movimentos percebem essa instabilidade, embora em sua concepção (e desejo), os seus interesses/demandas são sempre os mais importantes, os mais universais, os mais legítimos.

Acreditar nos conselhos representa, para esses agentes dos movimentos, muito mais o ponto de partida ${ }^{77}$ de um processo de democratização, em consequência dos "discursos conservadores" inscritos na cultura política. Por isso, em seus documentos e falas, insistem na criação de uma nova cultura $^{78}$ e depositam suas esperanças nesses

\footnotetext{
${ }^{75}$ RANCIÈRE, op. cit.

${ }^{76}$ MARX, Karl. Glosas críticas marginais ao artigo: o rei da Prússia e a reforma social de um prussiano. Práxis, Itumbiara, n. 5, p. 69-91, out./dez. 1995.

77 No documento do ConCidades está expresso que ainda existem "desafios" para a implementação desse conjunto de leis e orientações, que vão depender do conjunto dos órgãos do Governo Federal, dos entes da Federação e sujeitos sociais que atuam no urbano. E vêem as Conferências como o início da "pactuação". Nesse discurso, essa política também depende de ampliação das fontes de financiamento, em todos os entes federativos. A proposta é construir "um planejamento em escala nacional", sempre partindo de "novos marcos legais de gestão pública e de cooperação entre os entes federados"; isso faz lembrar as ideias dos planos inscritas em diversos governos, guardadas as devidas diferenças.

${ }^{78}$ A partir da Constituição de 1988, vimos proliferar diversos espaços de "participação", que conseguiram êxito na elaboração de leis e normas que alteraram o patamar da cidadania. Mas existem diversas dificuldades apontadas pelos analistas (cf. OLIVERA, F. Crítica à razão dualista: o ornitorrinco. São Paulo: Boitempo Editorial, 2003. 150p.) na implementação do tal controle social. Essa implementação passaria por uma incorporação das
} 
processos participativos. Do ponto de vista formal, a legislação existente ainda não foi incorporada pelas gestões (estaduais e municipais), sobretudo no tocante à criação dos conselhos. A decisão final sobre o direcionamento dos recursos se dá no espaço legislativo e executivo, que envolve outras relações de poder. Assim, trata-se de uma disputa constante pela hegemonia, no sentido definido por Laclau e Mouffe. ${ }^{79}$ Nesse contexto, os agentes dos movimentos aprovavam a abertura propiciada pelo governo Lula, ao mesmo tempo em que muitas de suas decisões no Conselho das Cidades foram ignoradas.

Não há como negar que o volume de recursos para a habitação aumentou, diminuindo o déficit habitacional. ${ }^{80}$ Se no período de 1995 a março de 2000 foram beneficiadas 1.443.169 famílias (governo FHC), somente entre 2005 e 2007, mais 1.600 .000 tiveram o benefício. Segundo o relatório da Caixa Econômica Federal, as contratações realizadas na área de saneamento e infraestrutura totalizaram investimentos de $R \$ 2,2$ bilhões. O fato é que toda essa discussão nunca teve espaço como "política pública nacional de desenvolvimento urbano" (incluindo habitação e saneamento em ações em longo prazo), sobretudo num contexto de democracia. Uma política parecida só existiu no período da ditadura militar, mas com grande custo e repressões. ${ }^{81}$

Recebido em 10/05/2012

Aceito para publicação em 15/06/2012

noções de direito afirmadas nessa legislação, tanto do ponto de vista do Estado, quanto da sociedade. Não é à toa que Gohn, op. cit., denominou esse período como a era dos direitos para os movimentos sociais.

${ }^{79}$ LACLAU, Ernesto; MOUFFE, Chantal, op. cit.

${ }^{80}$ IPEA, 2007.

${ }^{81}$ TAVARES, M. C.; ASSIS, J. C. O Grande Salto para o Caos: A Economia Política e a Política Econômica do Regime Autoritário. Rio de Janeiro: Jorge Zahar Editor, 1985; MARICATO, Ermínia. As idéias fora do lugar e o lugar fora das idéias. In: ARANTES, Otília et al. (org). A cidade do pensamento único: desmanchando consensos. Petrópolis: Vozes, 2000. 